\title{
GENETICS OF TERPENES \\ I. GENE CONTROL OF MONOTERPENE LEVELS IN PINUS MONTICOLA DOUGL.
}

\author{
JAMES W. HANOVER \\ Geneticist, Forestry Sciences Laboratory, Intermountain Forest and \\ Range Experiment Station, U.S. Department of Agriculture, Moscow, Idaho *
}

\section{INTRODUCTION}

Received 10.v.65

Differences in terpenoid levels between plant species are known to exist but little is known about their genetic bases. The terpenes have been used extensively in biochemical systematic studies in Pinus (Mirov, 1958, 1961; Williams and Bannister, 1962; Forde, 1964), Eucalyptus (Baker and Smith, I920; Penfold and Morrison, 1927), Cupressacee (Erdtman, 1958), and many other plant families and genera (Alston and Turner, 1963 ). These studies were usually based upon the assumption that variation within a species is relatively small. Although this may be valid in some cases, Bannister et al. (1962) and others have shown that the level of terpenes can vary with geographic origin within a species. Recent data on tree-to-tree variability in the monoterpenes of Pinus ponderosa Laws. show that such variation can be relatively large (Smith, 1964). Results of similar work in our laboratory with western white pine (Pinus monticola Dougl.) also revealed substantial qualitative and quantitative variation in the cortex monoterpenes between trees.

In order to provide a basis for the use of terpenes for comparative biochemical studies, an understanding of both their variability and mode of inheritance is essential. The objective of the present study is to demonstrate the degree to which levels of six monoterpene compounds are gene-controlled in western white pine. Interrelations among the terpenes and between terpenes and growth are also considered.

\section{MATERIALS AND METHODS}

The materials for this study are of three types: (I) parents-as clonal lines of grafts, (2) $F_{1}$ progeny from crosses between the ortets (parents) represented by the clones, and (3) $S_{1}$ progeny of the parent trees.

Six to eight grafted plants from each of the nine different clones were selected for analysis. The clones are growing within a 17 -acre experimental plantation at Sandpoint, Idaho. Scions from the mature parent trees were greenhouse grafted on ordinary western white pine rootstocks in the winter of $195^{8-59}$, then outplanted in 196o. Seventy $F_{1}$ plants about 12 years old are included in the study. They represent 17 different crosses among the 9 parents and are growing in an experimental

* Present address: Greeley Memorial Laboratory, School of Forestry, Yale University New Haven, Connecticut. 
arboretum at Moscow, Idaho. The third group of plants analysed were also growing at Moscow and were composed of $24 S_{1}$ seedlings, about 12 years old, derived from selfing each of the parents (ortets).

Samples of oleoresin, which includes the monoterpenes, were taken from all plants early in October by the following procedure: a shallow cut was made with a scalpel into the phloem of I-year-old internodes. This resulted in an immediate exudiation of oleoresin which was quickly drawn into a glass capillary tube to minimise exposure to air. Thirty $\mu$ l. of the resin were collected as it flowed from the wound. The capillary tube containing the sample was placed in a sealed centrifuge tube and refrigerated until ready for analysis.

Just before a sample was to be analysed, it was diluted with $50 \mu l$. of acetone. A $4 \mu$ l. aliquot from this solution was injected into the chromatograph. The monoterpenes were analysed with an F\&M Model 500 gas chromatograph with a Model 1609 flame ionisation detector. The column was $4^{\prime \prime} \times 5^{\prime}$ stainless steel packed with Io per cent. polypropylene glycol on 6o-80 mesh Diatoport W-AW. Column temperature was $100^{\circ} \mathrm{C}$., injection port was $230^{\circ} \mathrm{C}$., detector was $225^{\circ} \mathrm{C}$., and helium flow rate was $40 \mathrm{ml}$./minute.

The monoterpenes were identified by comparing relative retention times of the unknowns with those of known compounds. In addition, known monoterpenes were added to white pine samples to verify identity by peak enhancement. To substantiate identifications, a similar procedure was followed using a non-polar (Apiezon L) column packing in contrast to the polar polypropylene glycol packing. The operating conditions for Apiezon L were: the column was $1^{\prime \prime} \times 6^{\prime}$ stainless steet packed with 10 per cent. Apiezon L on 6o-8o mesh Diatoport W-AW, column temperature was $135^{\circ} \mathrm{C}$., injection port and detector temperatures were both $195^{\circ} \mathrm{C}$.。 and helium flow rate was $35 \mathrm{ml}$./minute.

Quantitative determinations were made by measuring areas under the peaks as estimated by the product of peak height times width at $\frac{1}{2}$ peak height. Concentration of a component is proportional to peak area when all operating conditions are constant (Pecsok, 1959). The area values were used directly as the measure of terpene level for all statistical analyses. The total terpene content was obtained by summing all values for the individual terpenes.

Growth measurements on all plants are expressed as periodic annual increment. To account for bias due to unequal family sizes in the regression analyses, the method of Kempthorne and Tandon (1953) and Reeve (1955) was used to derive appropriate weighting factors. All statistical analyses were performed on an IBM 709 computer.

\section{RESULTS}

Qualitative determinations revealed at least eight detectable responses in white pine oleoresin. One of the terpenes (no. 8, fig. I) is present only in trace quantities and is not considered in this study. Another (no. 7, fig. I), tentatively identified as myrcene, was not separated from 3-carene by the procedures used in this study. However, some separation of myrcene and 3-carene could be achieved by increasing the column length to 6 feet, decreasing the column temperature to $95^{\circ} \mathrm{C}$. and increasing carrier gas flow rate to $160 \mathrm{ml}$./minute (fig. I). The remaining six monoterpenes are designated as alphapinene, camphene, beta-pinene, 3-carene, limonene, and unknowns 6 and 8 (fig. I). The possibility of traces of undecane being obscured by limonene could not be eliminated by co-chromatography using columns of different polarity. Camphene, 3-carene and myrcene have not been reported previously in Pinus monticola Dougl.

A comparison of the variation in a trait within and between clones 
gives a broad sense estimation of the relative effect of environment and heredity on the trait $\left(h^{2}\right.$, broad sense). Sometimes, clonal studies may be stratified over different environments. Only a single environment (the r 7 -acre clonal planting) is considered in the clonal analysis of the present study.

Representative terpene chromatograms of five of the nine white pine clones (i.e. parents, ortets) studied are in fig. 2. The combinations of

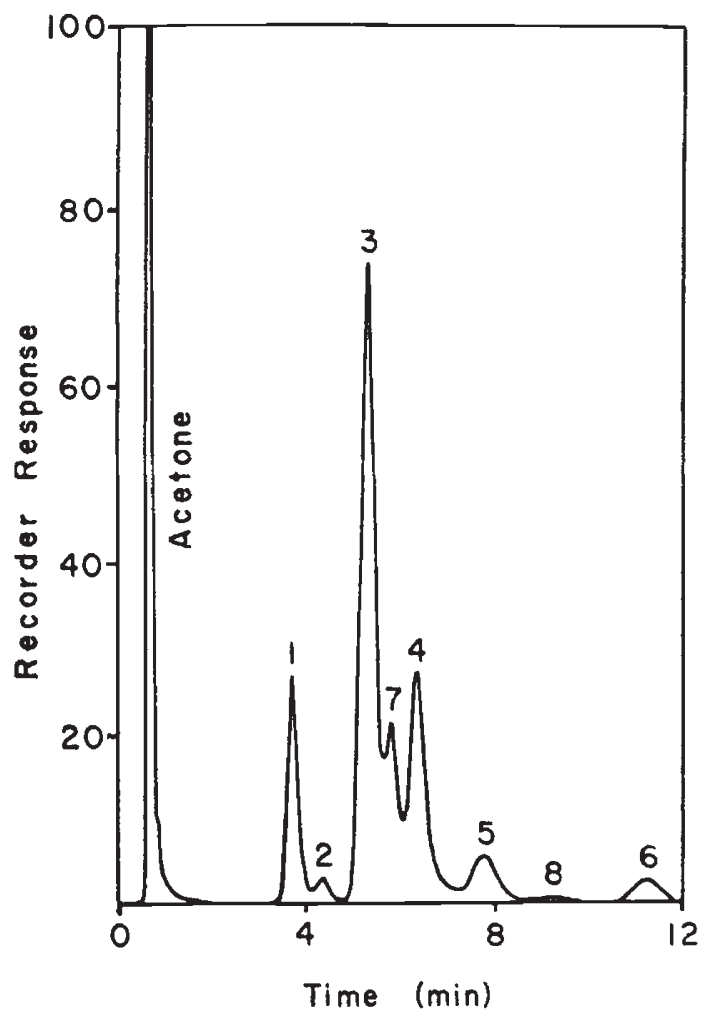

Fig. 1.-Chromatogram of Pinus monticola Dougl. oleoresin in acetone. Stationary phase: Io per cent. polypropylene glycol on 6o-80 mesh Diatoport W-AW. Monoterpenes I-5 and 7 are tentatively identified as (1) alpha-pinene, (2) camphene, (3) beta-pinene,

(4) 3-carene, (5) limonene, and (7) myrcene. Numbers 6-8 have not been identified.

terpene levels among clones are obviously quite varied. However, individual members of each clone are remarkably similar in their terpene pattern.

The results of variance analyses on the clonal data are expressed in terms of F-values in table $\mathrm{I}$. The levels of each terpene and total terpenes are strongly associated with genotype. In contrast, growth rate varies considerably but shows little association with genotype. The broad sense heritability estimates also given in table I indicate moderate to strong genetic control of the terpenes and weak genetic control of growth rate. 
Analyses of $70 \mathrm{~F}_{1}$ hybrid plants representing $\mathrm{I} 7$ crosses among the cloned parents used in this study show that growth rate and level of
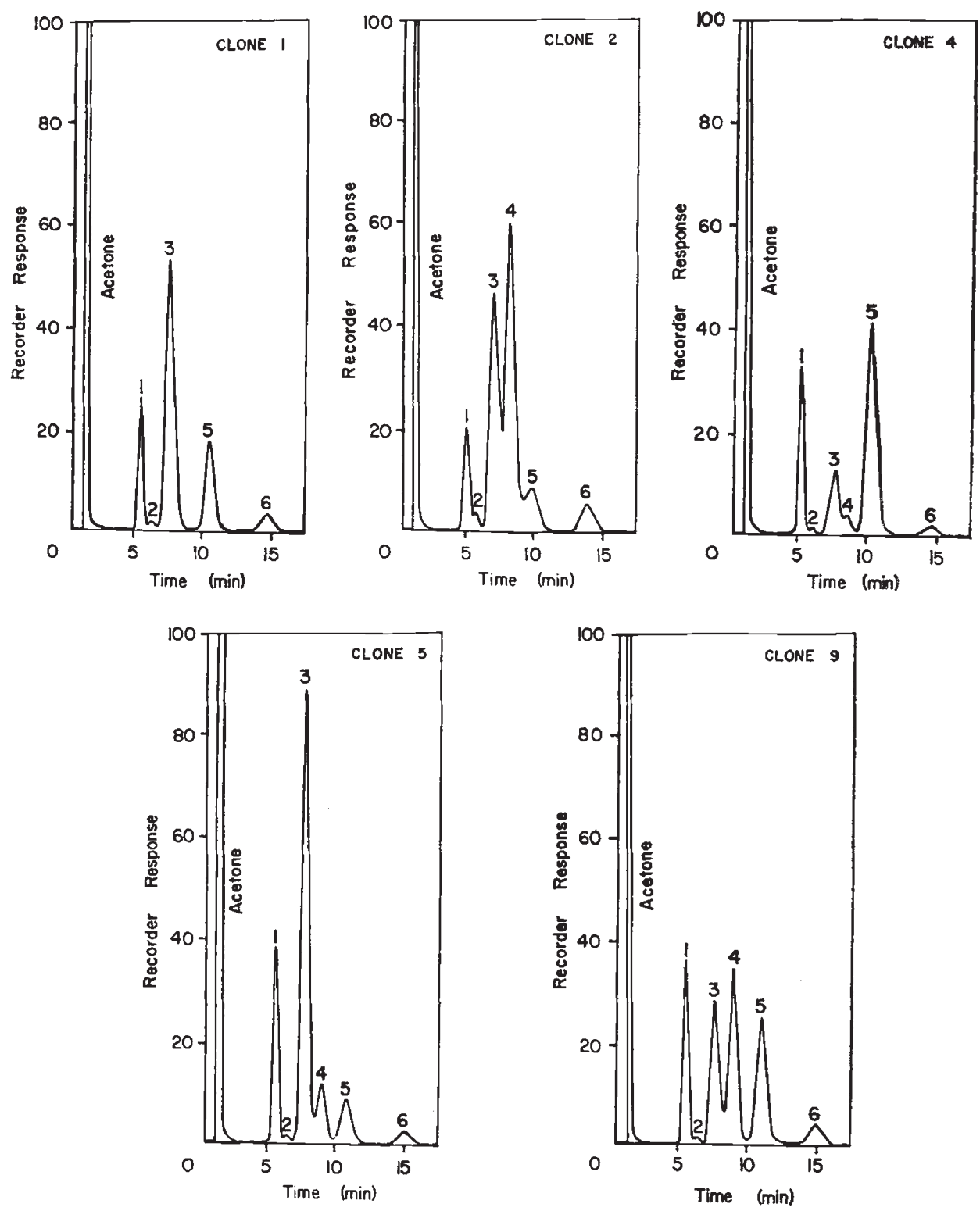

Frg. 2.-Typical chromatograms of oleoresin from five western white pine clones showing qualitative and quantitative variation in six monoterpenes identified in fig. I. Stationary phase: 10 per cent. polypropylene glycol on Diatoport W-AW. Column is $1^{\prime \prime} \times 5^{\prime}$, column temperature is $100^{\circ} \mathrm{C}$., and helium flow rate is $4^{\circ} \mathrm{ml} . / \mathrm{minute}$.

each terpene except camphene vary significantly among crosses (table 2). Although the total monoterpene content of the oleoresin is 
significantly associated with progeny groups, this variable is probably confounded by correlations with the individual terpenes that contribute to its estimation.

TABLE I

F-values and broad sense heritability estimates for monoterpene levels and growth rate of white pine clones

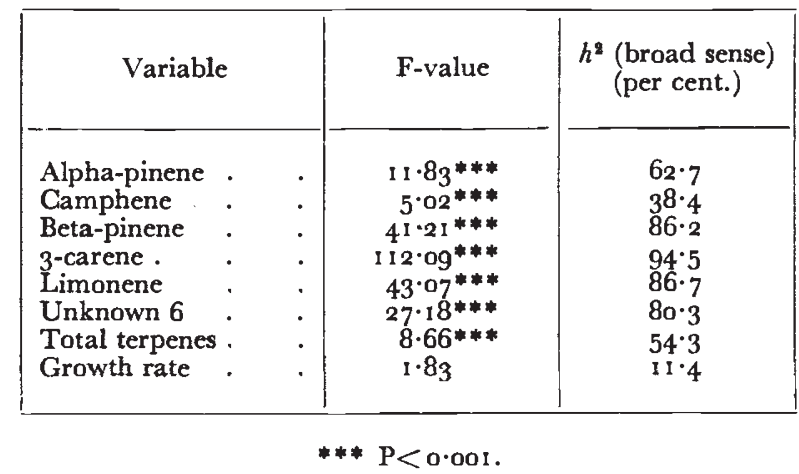

The regression of offspring on either one of their parents or on the midparent value for a trait estimates one-half of the additive genetic variance when the single parent is used and total additive genetic

TABLE 2

$F$-values from analyses of variance among and within $F_{1}$ hybrid progenies for western white pine monoterpene levels and growth rate

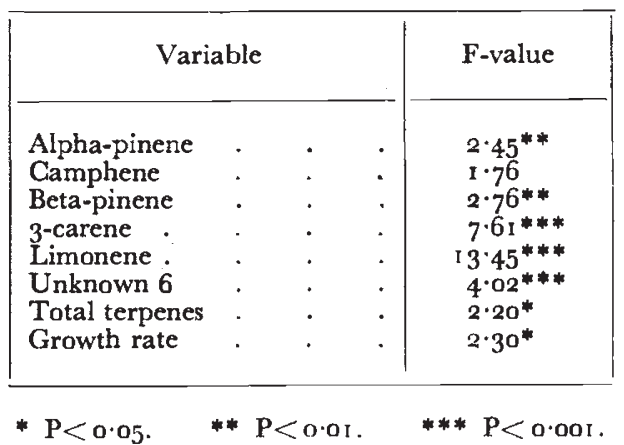

variance when midparent is used (Falconer, I960). Results of regression analyses using all three methods for each variable are in table 3. As in the clonal analysis the genetic control of quantity produced is high for alpha-pinene, beta-pinene, 3-carene, limonene, unknown 6 and total terpenes. Much of the genetic variance for these traits appears to be additive. For growth rate and camphene the data indicate very low additive genetic control.

To understand the genetics of chemical traits such as the terpenes 
it is desirable to know something about their relationships with each other as well as with other traits of interest. Simple correlation analyses provide this information for white pine monoterpenes and growth rate (table 4). There are significant positive correlations

TABLE 3

Results of regression of each parent and midparent value on offspring for western white pine monoterpenes and growth rates

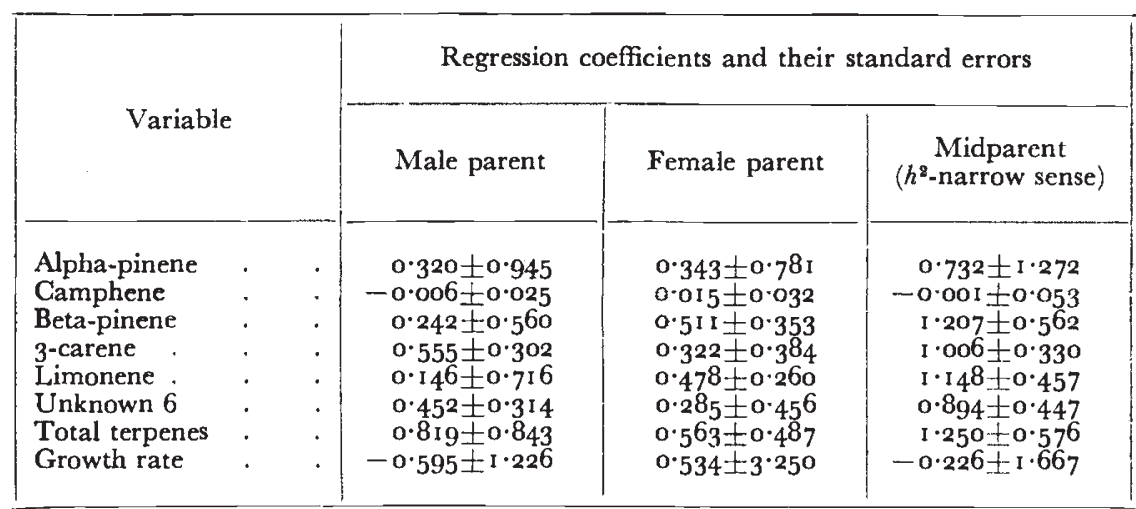

between amounts of alpha-pinene and limonene, and between 3-carene and unknown 6 . There are significant negative correlations between beta-pinene and 3-carene, 3-carene and limonene, and limonene and

TABLE 4

Simple correlation coefficients for western white pine monoterpene level and growth rate $(68$ d.f.)

\begin{tabular}{|c|c|c|c|c|c|c|c|}
\hline Monoterpene & Camphene & $\begin{array}{l}\text { Beta- } \\
\text { pinene }\end{array}$ & 3-carene & Limonene & Unknown & Total & Growth \\
\hline $\begin{array}{l}\text { Alpha-pinene } \\
\text { Camphene } \\
\text { Beta-pinene } \\
\text { 3-carene } \\
\text { I.imonene } \\
\text { Unknown } 6 \\
\text { Total terpenes }\end{array}$ & $0 \cdot 13^{8}$ & $\begin{array}{l}\text { o. I } 50 \\
\text { o' } 194\end{array}$ & $\begin{array}{c}-0.169 \\
0.142 \\
-0.279^{*}\end{array}$ & $\begin{aligned} & 0.25^{*} \\
&-0.131 \\
&-0.136 \\
&-0.34^{* *}\end{aligned}$ & $\begin{array}{l}-0.132 \\
0.199 \\
-0.16 \mathrm{I} \\
0.625^{* * *} \\
-0.26 \mathrm{I}^{*}\end{array}$ & $\begin{array}{l}0.436^{* * * *} \\
0.263^{*} \\
0.65^{* * *} \\
0.322 * * \\
0.069 \\
0.237^{*}\end{array}$ & $\begin{array}{l}-0.322 * * \\
-0.093 \\
-0.176 \\
-0.143 \\
-0.123 \\
0.108 \\
-0.3^{8} 3^{* *}\end{array}$ \\
\hline
\end{tabular}

$$
\text { * } \mathrm{P}<0.05 . \quad \text { ** } \mathrm{P}<0.01 . \quad \text { *** } \mathrm{P}<0.001 .
$$

unknown 6. All terpenes are positively correlated with total terpene content and all correlation coefficients were significant except the one for limonene. This might be expected since each contributes to the estimate of the total.

All the terpenes except unknown 6 are negatively correlated with growth rate in white pine although only the correlation coefficients for alpha-pinene and total terpenes are significant. 


\section{DISCUSSION}

The results of these western white pine cortex monoterpene analyses substantiate Smith's ( 1964 ) observation of wide tree-to-tree differences in relative per cent. composition of ponderosa pine terpenes from wood oleoresin. What differences may exist between these two sources within a plant are not known. Mirov (I96I) reported that wood oleoresin from $P$. monticola was composed of $n$-heptane, alpha-pinene, beta-pinene, limonene, undecane and bornyl acetate. He found no camphene, 3-carene, or myrcene as reported in the present study.

Genetic statistical analyses of these chemical traits have clearly demonstrated that levels of five of the six monoterpenes are highly regulated by gene action. Narrow sense heritability estimations based upon either one of the parents and on midparent values fluctuate around unity when standard errors are considered (table 3 ). The regression coefficients based upon single parent data are roughly onehalf the value of those derived from midparent data (table 3 ). Theoretically, this is the expected result for quantitatively inherited traits (Falconer, I96o), although the possibility of major gene control of terpene level certainly cannot be eliminated.

The five identified white pine monoterpenes are closely related structurally (Haagen-Smit and Nimmo, I963) and possible molecular rearrangements in terpenoids in general are numerous. Such rearrangements can be attributed to many factors including acid or base catalysis, heat, light, etc. (King and de Mayo, I964). The role of enzymes in these rearrangements and the question of just how genes mediate the quantitative production of specific terpenes, of course, we don't know. From the significant correlations, both positive and negative, between white pine monoterpenes in this study (table 4) one can speculate about certain interrelationships that appear to exist. For instance, there is some evidence that limonene can be derived from alpha-pinene (King and de Mayo, I964), thus the positive correlation between these two compounds. The high correlation between 3-carene and unknown 6 may indicate a common biosynthetic pathway dependent upon the same precursors for each compound. The significant negative correlations between beta-pinene and 3-carene, limonene and 3-carene, and unknown 6 and limonene suggest the possibility of alternate pathways from a common precursor to each pair of compounds. Swain (1962) pointed out that little is known about the regulatory mechanisms of organisms that give rise to gross differences in biosynthetic ability. Ultimately, the elucidation of biosynthetic pathways must include the identification of enzyme systems that catalyse the individual reaction involved. Only when this is accomplished can we understand the actual genetic regulatory mechanisms for monoterpenes.

Estimates of genetic variance derived from both clonal and parentprogeny data should also provide estimates of non-additive genetic 
variance by their difference. For instance, the terpene, camphene, shows genetic variation in the clonal analyses (table I) but virtually none in the parent-offspring regression analyses (table 3 ). This may
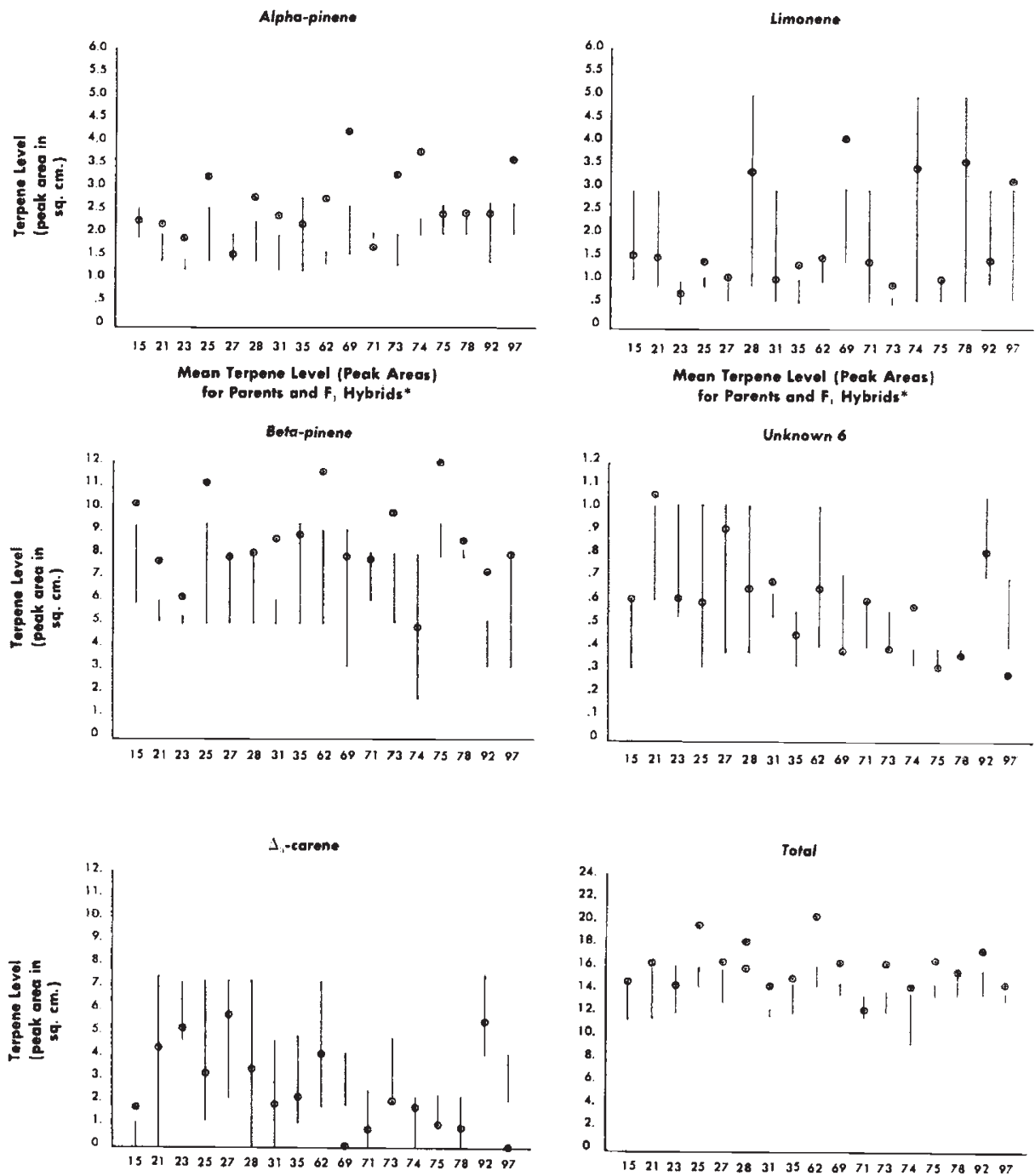

"The numbers an the abscissia indicate F, progeny groups. Each clone is numbered from
1 to 9. The cross designated "15" would have clone numbers I and 5 as the two parents.
etc. The ends of each vertical line represent the two parental values and the circled dot ele. The end the circled dot

Fig. 3.-Mean terpene levels for western white pine parents (clones) and their $F_{1}$ hybrids. indicate that the amount of camphene synthesised is mainly due to nonadditive gene action. The other terpenes in this study produce very high estimates for both total and additive genetic variation. The standard errors for regression coefficients in table 3 are too high to allow estimation of the non-additive gene effects by comparison with the 
clonal data. Both sets of data show that the levels of terpenes, except for camphene, are quite precisely gene-regulated. The parent-offspring data indicate that the average effects of the genes involved are highly additive if inheritance is polygenic.

The experiments described here were not designed specifically to provide information about the number of genes or type of gene action involved in terpene biosynthesis. However, when the average levels of each terpene in parents (clones) and $F_{1}$ progeny are plotted as in fig. 3 the results are illuminating. Terpene level appears to result from some form of heterosis, since progeny means generally exceed either midparent or both parental values. Tabulation of the mean terpene levels for all parents, $F_{1}$ progeny, and $S_{1}$ progeny shows that both 3 -carene and limonene tend to be lower in $F_{1}$ progeny than in the parents (table 5). For alpha-pinene, beta-pinene, unknown 6, and

TABLE 5

Mean terpene levels for all western white pine clones, $F_{1}$ progeny and $S_{1}$ progeny

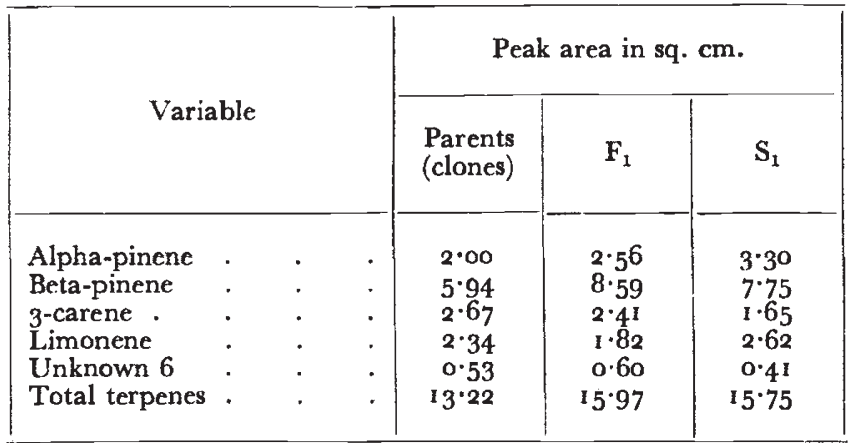

total terpenes the reverse is true. It is difficult to understand the genetic basis for higher or lower terpene levels in self-fertilised progeny than in both their parents and the $F_{1}$. This unique situation occurred in alpha-pinene (higher) and 3-carene (lower). Although both heterosis and inbreeding depression are thought to depend on directional dominance, epistatic interaction between loci may also be involved, particularly in natural populations of outbreeding plants such as Pinus spp. (Falconer, I960). Without knowledge of the type of gene control, expected values for terpene levels in $S_{1}$ progenies would be $\frac{1}{2}$ (parent $\left.+F_{1}\right)$. However, only beta-pinene level and total terpene level agree reasonably well with this expectation. Therefore, genetic interpretation of these rather unusual results must await further tests.

As pointed out earlier, the data presented in this study do not eliminate the possibility that the level of a given terpene may be determined by a more simple mode of inheritance. In fact, when individual tree data are examined there are some indications that only a few genes are involved. Some grouping of terpene level values occurs 
which is also evident in fig. 3, but a precise interpretation of the mechanism of gene control of terpene level is not yet possible.

It should also be emphasised that the possibility of terpene level differences due to differences in tissue ages between parents and progenies has not been eliminated. Such age differences would be of considerable interest from the physiological standpoint if they do exist. Other factors that conceivably could produce non-random effects on terpene levels in this study include rootstock or grafting in vegetatively propagated (parents) versus seed-propagated $\left(\mathrm{F}_{1}\right.$ and $\left.\mathrm{S}_{1}\right)$ plants.

\section{CONCLUSIONS}

The data presented here for growth rate and quantitative amounts of monoterpenes offer an interesting contrast between traits under weak genetic control and those under strong genetic control. The results also emphasise certain points that should be considered in chemotaxonomy studies. First, one should know something about the qualitative variability of chemicals within a species. This is an important prerequisite to inferences about differences between species. For instance, the genotype represented by clone I (fig. 2) apparently is not capable of synthesising 3-carene, which, based upon most plants of the species, might be called diagnostic of Pinus monticola Dougl. oleoresin. Second, the great quantitative variation in terpenes within a species shows that relative amounts are by no means uniformly characteristic of a species. Therefore, caution is necessary when terpene patterns are described in terms of ratios of one component to another.

The strong genetic control demonstrated for these chemical traits in western white pine can be useful in several ways for future genetic studies in this species and perhaps others. The inclusion of one lowheritability physiological trait, growth rate, in this study is an attempt to illustrate a potential use of biochemical traits in breeding programmes. For example, the significant negative correlations between alpha-pinene and growth, or total terpene content and growth, suggest the possibility of indirect selection for growth rate. Such a procedure may be more efficient than present methods, particularly for physiological traits that are subject to much environmental influence.

The results of this study imply that the validity of natural or artificial crosses within species can be determined easily. Finally, the monoterpenes of western white pine may prove to be suitable markers for population genetic studies in this and other species which are distributed over diverse environmental gradients.

In the future much emphasis will undoubtedly be placed on the quantitative study of biochemical traits for genetic, systematic and physiologic purposes.

\section{SUMMARY}

Alpha-pinene, camphene, beta-pinene, 3-carene, limonene, one unidentified terpene and total terpene content of cortex oleoresin in 
clones, $\mathrm{F}_{1}$ hybrids, and $\mathrm{S}_{1}$ progeny of Pinus monticola Dougl. were quantitatively analysed using gas-liquid chromatography. The level of each monoterpene in a standard volume of oleoresin is shown to be significantly associated with genotype. The inheritance of each terpene except camphene is additive and also appears to include some heterotic or epistatic effects. Growth rate of the plants is negatively correlated with alpha-pinene and total terpenes $(\mathbf{P}<0 \cdot 0 \mathrm{r})$. Other significant negative correlations exist between beta-pinene and 3-carene, 3-carene and limonene, and limonene and the unidentified terpene. Positive correlations appear between alpha-pinene and limonene and between 3 -carene and the unknown. The results indicate that some of the many possible molecular rearrangements in the terpenoids are under fairly rigid genetic regulation.

Acknowledgments. - The author is very grateful to the Washington State University Computing Center, Pullman, Washington, for the use of their facilities and to Dr T. Bogyo for aid in programming the data. Samples of known monoterpenes were kindly provided by Dr R. H. Smith, U.S. Forest Service, Berkeley, California.

\section{REFERENCES}

Alston, R. E., AND tURner, B. L. I963. Biochemical Systematics. 404 pp. PrenticeHall, Inc., New Jersey.

BAKER, R. T., AND SMITH, H. G. I920. Research on the eucalypts especially in regard to their essential oils. Ed. 2, Sydney Technol. Mus. N.S. Wales Tech. Educ. Ser. No. 13 .

BANNISTER, M. H., WILLIAMS, ALLETTE L., MCDONALD, I. R. C., AND FORDE, MARGOT B. 1962. Variation of turpentine composition in five population samples of Pinus radiata. New Zealand Four. Sci., 5, 486.495.

ERDTMAN, H. 1958. Conifer Chemistry and Taxonomy of Conifers. IV. Internatl. Cong. Biochem., Vienna. II. Pergamon, New York.

falconer, D. s. 196o. Introduction to Quantitative Genetics. Ronald Press, New York. FORDE, MARGOT B. I964. Inheritance of turpentine composition in Pinus attenuata $\times$ radiata hybrids. New Zeal. Four. Bot., 2(I), 53-59.

HAAGEN-SMIT, A. J., AND NIMmo, C. C. I963. Chemistry of isoprenoid compounds, pp. I I 5-168. In Florkin, Marcel and Stots, Elmer H. (eds.), Comprehensive Biochemistry. Elsevier, New York.

KEMPTHORNe, O., AND TANDON, O. B. 1953. The estimation of heritability by regression of offspring on parent. Biometrics, 9, 90-Ioo.

KING, J. F., AND DE MAYO, P. I964. Terpenoid rearrangements, pp. 77I-840. In de Mayo, P. (ed.), Molecular Rearrangements. Interscience, New York.

MIROV, NIGHOLAS T. I958. Distribution of turpentine components among species of the genus Pinus, pp. 25I-268. In Thimann, K. F. (ed.), The Physiology of Forest Trees. Ronald Press, New York.

mirov, Nigholas T. I96I. Composition of gum turpentine of pines. U.S. Dept. Agr. Tech. Bull., I239, I $5^{8}$ pp.

PECSOK, R. L. 1959. Principles and Practice of Gas Chromatography. 226 pp. John Wiley, New York.

PENFOLD, A. R., AND MORRISON, F. R. I927. The occurrence of a number of varieties of Eucalypius dives as determined by chemical analyses of the essential oils. Part I. Four. and Proc. Roy. Soc. N.S. Wales, 6I, 54-67.

REEVE, E. C. R. I955. The variance of the genetic correlation coefficient. Biometrics, $r I, 357-374$. 
SMTTH, RIGHARD H. 1964. Variation in the monoterpenes of Pinus ponderosa Laws. Science, $143,1337-1338$.

swaIN, T. 1962. The biosynthesis of polyphenols, pp. 277-313. In Hillis, W. E. (ed.), Wood Extractives and their Significance to the Pulp and Paper Industries. Academic Press, New York.

WILlIAMs, ALlETTE L., AND BANNISTER, M. H. I962. Composition of gum turpentines from twenty-two species of pines grown in New Zealand. Pharm. Sci., 5I, 970-975. 